\title{
30kW DC-DC Converters with Regenerative Mode for Electric Cars
}

\author{
Federico Ibáñez ${ }^{\dagger}$, Javier Vadillo*, Miguel Martínez-Iturralde Maiza*, and José Martín Echeverría* \\ ${ }^{\dagger *}$ Dept. of Electronics and Communications, CEIT, San Sebastián, Spain
}

\begin{abstract}
This paper presents a design of a 30kW 250V/530V bidirectional DC-DC converter to be used in an electrical car. A detailed explanation of the design is given. The system uses two phase shifted half bridge (boost and buck) topologies to reduce the ripple current in the output capacitor. The converter has an efficiency of $95 \%$ at nominal power. It works as a constant voltage in one direction and as a constant current in the other to charge the batteries. Simulations and measurement are done at high power to test the efficiency.
\end{abstract}

Key words: Bidirectional, DC-DC Converter, Electric Car, High Power, Phase Shifted

\section{INTRODUCTION}

Nowadays, electric and hybrid cars are gaining importance as well as the power electronics for these issues. All of these systems require a voltage bus where each energy storage and loads are linked [1], [2]. In general, the storage systems output voltage can vary within a certain range so a DC-DC converter is required to share the energy in the voltage bus at a constant voltage.

These converters involve high power transfer in both directions. As the converter is inside a car, the weight, volume, efficiency and safety are important issues.

The present work is a part of an electric car which will participate in a competition in Barcelona, Spain in 2011. It consists of a design of a high power DC-DC converter. The paper is a useful guideline to design DC-DC converters at electric vehicle power levels.

The electrical diagram of the car, to control the motors, is simple as can be seen in Fig. 1. There are four main blocks: two batteries, two DC-DC converters, four motor drives and the motors themselves.

The batteries are Lithium-ion Ferrous Phosphate Battery. They have their own protection for temperature, overcurrent and over/undervoltage. Both battery stacks have a voltage between $280 \mathrm{~V}$ and $240 \mathrm{~V}$ in a normal condition.

Manuscript received May 21, 2011; revised Dec. 9, 2011

Recommended for publication by Associate Editor Yong-Chae Jung.

†Corresponding Author: fmibanez@ceit.es

Tel: +34-943-212800, Fax: +81-836-85-9401, CEIT

*Dept. of Electronics and Communications, CEIT, Spain

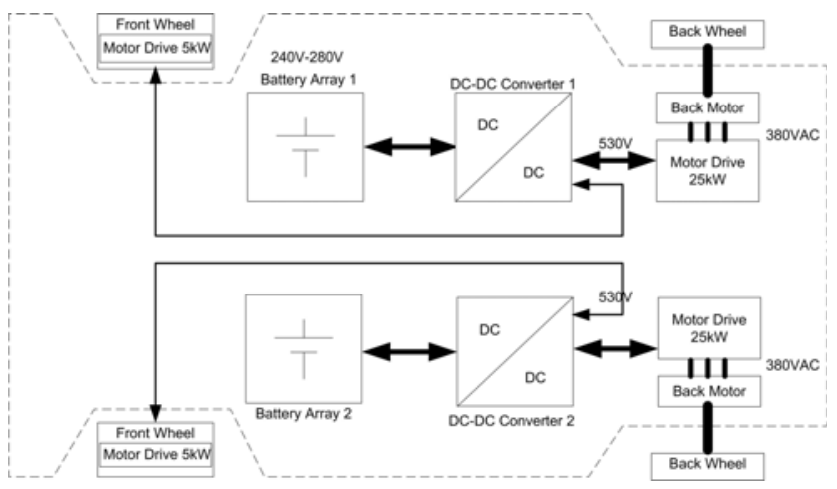

Fig. 1. Block Diagram of the car.

Each DC-DC converter energizes two motor drive stages: one for a back motor and the other for the front one. The nominal power of each converter is $30 \mathrm{~kW}$ which is enough to drive the motors. This DC-DC converter is not only capable of powering the motors but also of charging the batteries at a constant current mode, so the converter is bidirectional. If the regenerated energy was beyond a certain limit, a resistor would be directly attached to the high voltage DC bus to limit the maximum voltage at $600 \mathrm{~V}$, which in turn protects the circuit.

The motor drive uses a vector control to adjust the torque and speed of the motors. Finally, there are four motors in the vehicle, two inside the front wheels and two for the back wheels but fixed in the chassis.

For safety reasons, all power systems are fully isolated from the control stage. It has a $24 \mathrm{~V}$ source to supply the control units; every sensor and actuator in the power stage is also fully 
TABLE I

SPECIFICATIONS FOR DC-DC CONVERTER FROM BATTERIES TO LOAD

\begin{tabular}{|c|c|c|c|}
\hline Parameter & Symbol & Value & Unit \\
\hline Output Voltage & $\mathrm{V}_{\mathrm{O}}$ & 530 & $\mathrm{~V}$ \\
Ripple Output Voltage & $\mathrm{rV}_{\mathrm{O}}$ & 5 & $\%$ \\
Maximum Output Power & $\mathrm{P}_{\mathrm{O}}$ & 30 & $\mathrm{~kW}$ \\
Minimum Input Voltage & $\mathrm{V}_{\text {IN_MIN }}$ & 240 & $\mathrm{~V}$ \\
Maximum Input Voltage & $\mathrm{V}_{\text {IN_MAX }}$ & 280 & $\mathrm{~V}$ \\
Minimum Efficiency & $\mathrm{n}_{\mathrm{MIN}}$ & 90 & $\%$ \\
\hline
\end{tabular}

isolated. In order to improve the safety, the main power can not be linked to the motor drives until the control is fully operative. Also many emergency buttons around the car immediately disconnect the main power stage.

\section{OBJECTIVE}

The objective is to build a bidirectional DC-DC converter capable of transferring up to $30 \mathrm{~kW}$. In one direction, it has to transfer the full power at a $530 \mathrm{~V}$ constant voltage output and in the other direction; it works as a fixed current source of 50A to charge the batteries at the maximum current level indicated by the manufacturer. The input voltage range, which depends on the battery array, is from $240 \mathrm{~V}$ to $280 \mathrm{~V}$.

The paper shows a quick and simple design methodology for this type of converters, which focuses on the power losses as a function of frequency.

\section{DC-DC CONVERTER DESIGN}

The design begins with the specifications which are shown in Table I.

\section{A. Power Converter Topology}

The topology selected is a Half-Bridge shown in Fig. 2. This topology has reduced components and also the ratio between the maximum and the average current in the switch is not too high when working in CCM. Other topologies have reduced switching losses but require a higher maximum current through the switching devices [3]-[7].

In one direction, the whole converter powers the motors with two $15 \mathrm{~kW}$ phase shifted boost stages in parallel in order to reduce the output capacitor ripple current. And in the other direction a single buck stage is used to deliver battery charge current.

\section{B. Frequency Selection - Power loss estimation}

The switching frequency was selected using the following criterion. All power losses are quantified as a function of frequency including losses in the semiconductor devices and

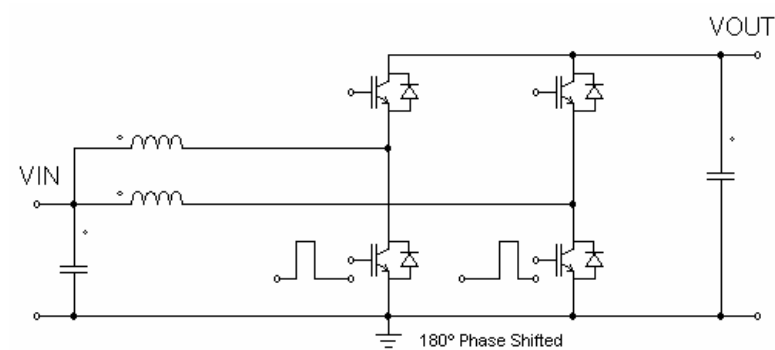

Fig. 2. Half-Bridge Converter. In one direction it is a Boost and in the other it is a Buck.

the inductor losses [8]. In the semiconductor both the conduction $\left(\mathrm{P}_{\mathrm{COND}}\right)$ and the switching losses $\left(\mathrm{P}_{\mathrm{SW}}\right)$ are taken into account. In addition, the inductor losses are divided in copper and core losses $\left(\mathrm{P}_{\mathrm{CORE}}\right)$. The copper losses are divided again in $\mathrm{DC}\left(\mathrm{P}_{\mathrm{CU} \_\mathrm{DC}}\right)$ and $\mathrm{AC}$ losses $\left(\mathrm{P}_{\mathrm{CU} \_\mathrm{AC}}\right)$. Then every loss is normalized with the total output power. So if an efficiency level needs to be guaranteed, a frequency range should be selected.

1) Semiconductor Power Losses: The expressions which were used to estimate the losses of the semiconductor devices are:

$$
\begin{gathered}
P_{C O N D}=I_{I N} \cdot D \cdot V_{C E S A T}+I_{\text {OUT }} \cdot(1-D) \cdot V_{F} \\
P_{S W}=\left.\left(E_{\text {ON }}+E_{\text {OFF }}+E_{R R}\right)\right|_{I_{I N}, V_{\text {OUT }}} \cdot f
\end{gathered}
$$

Where $I_{I N}$ and $I_{\text {OUT }}$ are the average input and output currents of the converter, $V_{\text {OUT }}$ is the output voltage, $f$ is the switching frequency, $E_{O N}, E_{O F F}, E_{R R}$ are switching energy losses for turn-on, turn-off and recovery process extracted from the datasheet as a function of the voltages and currents at the switching time, $D$ is the duty cycle, $V_{C E S A T}$ and $V_{F}$ are the voltage drop in the IGBT and diode forward drop respectively. The expressions above are a rough estimation of the real losses but give a first approach.

2) Inductor Design: The inductor losses depend on the inductance value, the number of turns, the gap, the core material and size and the copper section. In order to find the inductor losses, a quick design is presented.

The first step is: (a) to select the core and to assume that the core window area will be filled completely, (b) to limit a maximum current density. In our case, the current is limited at $4 \mathrm{~A} / \mathrm{mm}^{2}$ and the core used is EE10028 from Cosmos Ferrites. The maximum current can be estimated by the average power input and a ripple variation:

$$
I_{L_{-} M A X}=\frac{P_{O}}{n_{M I N} \cdot V_{I N_{-} M I N}}\left(1+\frac{r_{I}}{2}\right)
$$

Where $r_{I}$ is the ripple in the inductor current which is considered $30 \%$ for the first approach. Using the adopted 
current density and (3) the copper section is calculated $\left(A_{C U}\right)$.

The utility window factor $\left(k_{U}\right)$ is the ratio between the window area $\left(A_{W}\right)$ and the copper area $\left(N^{*} A_{C U}\right)$, normally it is below 0.5 but it is even less if the coil uses Litz wire. However, the benefits of using this kind of wire, the reduction in power losses, justify the costs and the limitation in $k_{U}$. In this prototype the coil is not made in an industrial process so $k_{U}$ is reduced again. In this design, due to our experience, only $k_{U}=0.15$ is set. This establishes the maximum number of turns.

$$
N=\frac{A_{W} \cdot k_{U}}{A_{C U}}
$$

Then, applying the Faraday law, the maximum variation in the flux density is obtained ( $\left.\Delta \mathrm{B}_{\mathrm{MAX}}\right)$ :

$$
\Delta B_{M A X}=\frac{V_{I N} \cdot D}{N \cdot A_{M} \cdot f}
$$

Where $A_{M}$ is the core section. The maximum flux density is given by:

$$
B_{M A X}=\frac{\Delta B_{M A X}}{2}+B_{D C}<B_{S A T}
$$

So the static point of the magnetic flux density $\left(B_{D C}\right)$ is limited.

Then, $\mu_{E}$ is obtained as:

$$
\mu_{E}=\frac{B_{D C} \cdot l_{M}}{\mu_{0} \cdot I_{I N_{-} D C} \cdot N}
$$

Where $l_{M}$ is the magnetic path; $I_{I N_{-} D C}$ is the DC current flowing through the inductor and $\mu_{E}$ is the equivalent relative magnetic permeability.

Once the number of turns is selected in (4) and $\mu_{E}$ is obtained in (6), using the material relative permeability, $\mu_{R}$, the gap (g) and the inductance are obtained:

$$
\begin{gathered}
g=l_{M}\left(\frac{1}{\mu_{E}}-\frac{1}{\mu_{R}}\right) \\
L=\mu_{0} \cdot \mu_{E} \cdot \frac{N^{2}}{l_{M}} \cdot A_{M}
\end{gathered}
$$

The inductance value is useful to calculate the inductor ripple current $\left(r_{I}\right)$, thus to iterate and to adjust the design.

3) Inductor Power Losses: The losses are extracted from this preliminary inductor design. The copper DC losses are now calculated as:

$$
\begin{aligned}
P_{C U_{-} D C} & =I_{I N_{-} D C}{ }^{2} \cdot R_{D C} \\
R_{D C} & =\frac{N \cdot M L T}{\sigma \cdot A_{C U}}
\end{aligned}
$$

Where $M L T$ is mean-length-turn and $\sigma$ is the copper

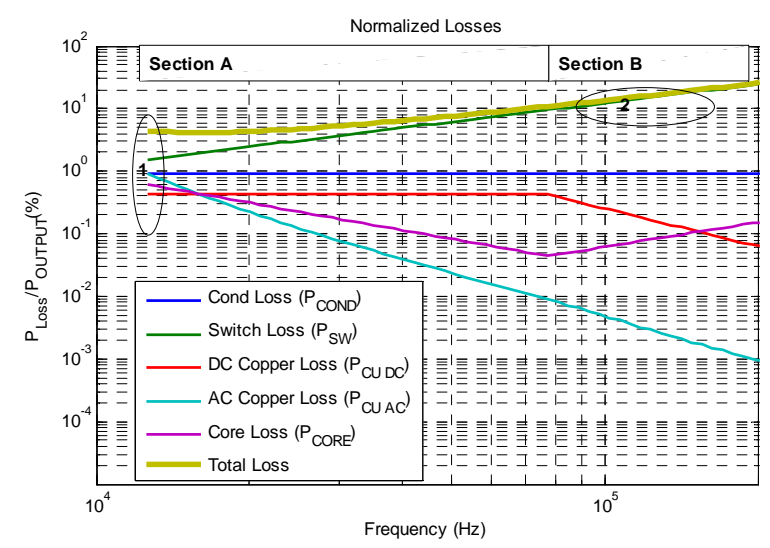

(a)

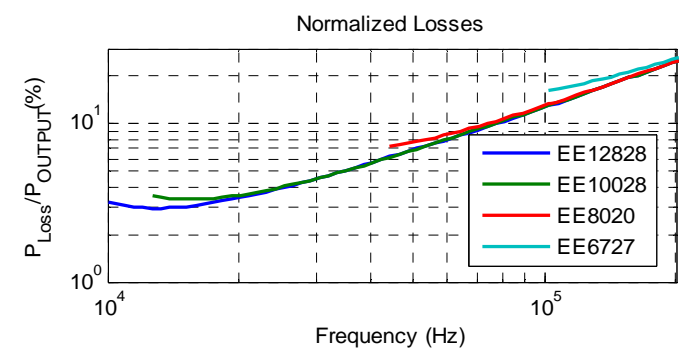

(b)

Fig. 3. Losses on a Boost Converter. (a) Different sources of losses for a Boost converter as a function of switching frequency. (b) Total losses with different cores.

conductivity.

The used wire has a radius of one skin-depth length ( $\delta \propto 1 / \sqrt{f}$ ), so the chosen wire diameter, the $A_{C U}$ and the $R_{D C}$ value are functions of frequency. In addition, the $A_{C U}$ is upper limited by the maximum window area, hence $R_{D C}$ is lower limited.

For the AC copper losses, the $F_{A C / D C}=R_{A C} / R_{D C}$ is calculated based on Dowell method [9, 10]. Therefore the power AC copper losses are:

$$
\begin{aligned}
P_{C U_{-} A C} & =I_{I N_{-} A C}{ }^{2} \cdot F_{A C / D C} \cdot R_{D C} \\
I_{I N_{-} A C} & =\frac{V_{I N} \cdot D}{2 \cdot L \cdot f \cdot \sqrt{3}}
\end{aligned}
$$

for a triangular wave.

Finally, the core losses are obtained using an empirical formula where the coefficients depend on the material used.

$$
P_{C O R E}=V_{N U} \cdot k_{1} \cdot f^{\beta} \cdot d B_{\max }^{\gamma}
$$

Where $. \gamma=2.8, \beta=1.7$, and $V_{N U}$ is the core volume, and $k_{l}=2.7$ for CF196 material.

Fig. 3 is a plot for previously calculated losses in (1), (2), (8), (9) and (10) as a function of frequency. The results show the frequency range which minimizes the losses. 
Two different slopes for the inductor losses $\left(P_{C U_{-} A C}, P_{C U \_}\right.$ and $\left.P_{\text {CORE }}\right)$ can be seen. The (A) section shows constant DC power losses and a monotonic reduction in AC and core losses. The constant DC losses are due to a constant copper wire diameter: the maximum current density and the input current lower limit $A_{C U}$, and thus, the window area in (4) limits the number of turns so $R_{D C}$ is constant in (8).

Because of the constant value of $N$, the flux density variation is monotonically reduced with the frequency (5) so the core losses are also reduced as in this kind of losses the reduction in the flux variation is more relevant than the frequency, $\gamma>\beta$ (10). Finally, the reduction in AC losses is due to the reduction in flux density variation, resulting in $I_{A C} . R_{D C}$ constant, $F_{A C / D C}$ is also constant if an adequate Litz wire for each frequency is used, hence $R_{A C}$ is kept constant.

This section ends when the flux variation reaches the minimum value imposed by the design $(50 \mathrm{mT})$. This value was selected to achieve total minimum losses.

In the (B) section, the number of turns can be reduced, and thus, the copper section can be incremented, so the DC losses fall (8).

The AC losses also fall due to the reduction in $R_{D C}$ and the constant value of $F_{A C / D C}$. Finally, the core losses increase because of the increment in frequency and the flux constant value (10).

Fig. 3(a) is obtained particularly with two cores EE10028 in parallel, increasing the core section and consequently, the inductance. The switching times and the voltage drop are extracted from the selected switch: the half-bridge IGBT 2MBI200SB-120 from FUJI. The figure 3b presents the total loss using different cores. The reduction in the operative frequency range when the core is reduced can be seen.

It is observed that for this topology the frequency range has a higher limit imposed by the switching losses (zone 2 in Fig 3a) and the lower limit (zone 1) is due to the saturation of the magnetic flux $\left(B_{S A T}\right)$. In this case, the operation range is between $20 \mathrm{kHz}$ and $40 \mathrm{kHz}$ for minimum losses. So a switching frequency of $20 \mathrm{kHz}$ was selected. The results of the inductor design are shown in Table II.

\section{Capacitor Selection}

The capacitor is selected in order to tolerate the current ripple $\left(I_{\text {CAP RMS }}\right)$, the bus voltage $\left(V_{O}\right)$ and it also should guarantee that the output ripple voltage is within the limits in Table I. Normally the capacitance obtained from the voltage ripple specification is much lower than the value derived from the capacitor RMS current parameter. This way, a decrease in the RMS current involves a reduction in the commercial capacitor value and size.

In order to reduce $I_{C A P \text { RMS }}$, two converters in parallel and $180^{\circ}$ shifted are used [11]. This produces a minimum current ripple for a single value of $D,(D=0.5)$ in comparison with a
TABLE II

PARAMETERS OF THE INDUCTOR

\begin{tabular}{|c|c|c|}
\hline \multicolumn{3}{|l|}{ Winding (Litz-Wire) } \\
\hline Diameter & 0.5 & $\mathrm{~mm}$ \\
\hline Number of conductors & 75 & - \\
\hline Copper Section & 14 & $\mathrm{~mm}^{2}$ \\
\hline Number of turns & 23 & - \\
\hline \multicolumn{3}{|l|}{ Core } \\
\hline Material & CF196 & \\
\hline Shape & 2 x EE10028 & \\
\hline Gap & 7.5 & $\mathrm{~mm}$ \\
\hline
\end{tabular}

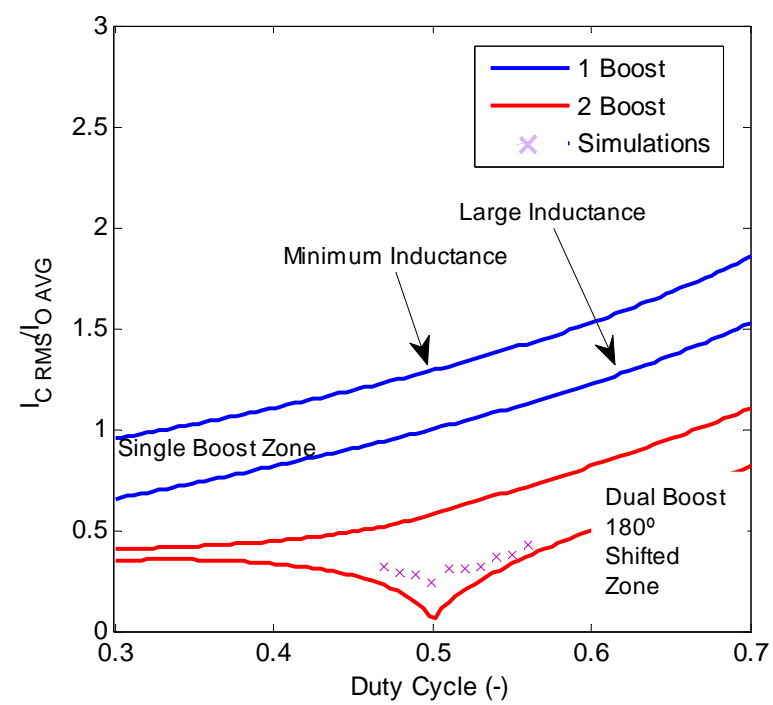

Fig. 4. Ratio between ripple capacitor current and the DC output current.

single boost and it also reduces the ripple around this minimum. In this case, the duty cycle of the converter ideally varies between 0.47 and 0.55 for different input voltages (240-280V).

Figure 4 plots the ratio between the ripple current and the output DC current for several cases. It compares the ripple for one boost with two $180^{\circ}$ phase shifted boosts. In addition, each case is plotted for the two limit conditions of CCM: infinite inductance (constant inductance current) and, DCM and CCM border inductance (triangular current). Any other case shall be placed between these two particular cases. This way, two operation regions, one for each topology, can be distinguished in the figure.

In this design, two $15 \mathrm{~kW}$ boost converters are designed to reach $30 \mathrm{~kW}$. From Table I, an output current of 56A ( $\left.I_{\text {OUT }}\right)$ can be obtained. Hence, a current ripple between 0.5 and 0.65 of $I_{O U T}$ can be deduced from Figure 4, taking into consideration the duty cycle mentioned before. So the maximum current ripple is 36A. 
In the prototype, the inductance value should be high to reduce the capacitor ripple current but; as the higher the inductance, the higher the volume and weight of the device; so a trade off exists. Also the limit in the capacitor current should be imposed by the capacitor itself.

The capacitor to be selected could be electrolytic or polypropylene type but either should tolerate the current ripple. The BHC ALS30A472QH350 (4700 uF) capacitor is chosen when considering the electrolytic solution. It can tolerate an RMS current up to 26A but only 350V. At least four capacitors are needed to build a 2x2 array that could support up to 52A current ripple at the output bus in the dual boost topology. The maximum current ripple in the circuit is below the capacitor specification so this array can be used. In order to reduce the volume of the whole converter the inductor should be selected to achieve a maximum ripple of 26A (not 36A), thus a parallel branch could be eliminated (simulations for this case are shown in Fig. 4). The capacitor array requires a balancing network. In this prototype a resistive balancing network is used because the voltage between them is not critical. In another situation, a more complex network should be employed [12], [13].

If the polypropylene alternative is chosen, the capacitance value should take into account the voltage ripple. The capacitance can be calculated using the current shape and the maximum value of voltage ripple ( $C=\Delta Q^{+} / \Delta V_{C}$ ). For example, if the voltage ripple is $5 \mathrm{~V}$, the capacitor should be greater than 100uF. The current is considered the same as in the electrolytic solution. The choice for this technology is a parallel array of 4 VISHAY $700 \mathrm{~V} / 80 \mathrm{uF} / 21 \mathrm{~A}_{\mathrm{RMS}} @ 85^{\circ} \mathrm{C}$ capacitors reaching $320 \mathrm{uF}$. This alternative offers a longer life-time (x5) and that is the reason why the polypropylene solution is more desirable.

\section{General Control Stage}

Fig. 5 shows a general diagram of the control stage. It consists of: a main oscillator, a frequency divider, a trigger pulse generator to synchronize each controller, both current mode controller for boost operation, a common current controller for buck operation, the power gate drivers and a switch which selects the power flow mode. There is a brief explanation of the stage in the following paragraphs.

The oscillator is a simple astable circuit; the T flip-flop uses the oscillator signal to generate two $50 \%$ square wave shifted $180^{\circ}$. Then the derivative circuit produces short pulses with the positive edge of each signal. These signals trigger the current-mode controller and its compensation ramp.

The system can work in two modes: as a power supply of $530 \mathrm{~V}$, using the Boost controller (low side switch and high side diode), or as a constant current supply in order to charge the battery due to regenerative braking.

\section{E. Power Flow Selector}

This module selects the operation mode. It consists of a single switch that can be controlled by a high level control

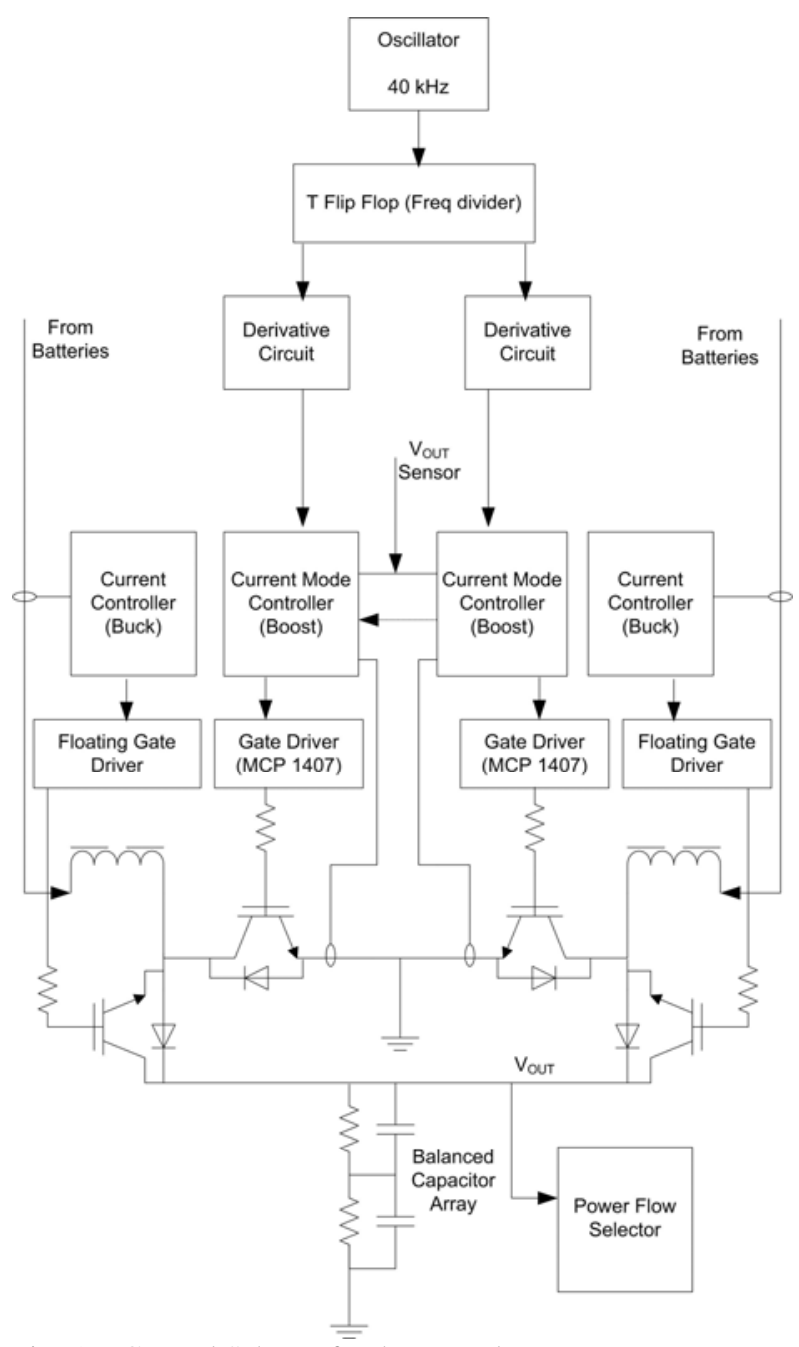

Fig. 5. General Scheme for the control stage.

(electronic control unit of the car) or by a control signal derived from the out, or using the output voltage.

The first option could be used in a noisy ambient, so a high level controller indicates when it is time to recover the energy. In the second case, a comparator with hysteresis triggers the buck controller when the output voltage reaches the normal mode voltage limit. If the output voltage drops below the buck-mode turn-off limit, the buck controller shuts down.

The lower voltage limit is above the operation voltage, i.e. $550 \mathrm{~V}$, so the buck controller is always turned off before the buck starts its operation. The high voltage limit is set to $580 \mathrm{~V}$.

\section{F. Boost Controller Stage (Powering)}

The controller uses an LEM-LV25 and HAS-200 Hall Effect sensors to capture the output voltage and switch current. It is a PWM current-mode boost that requires a compensation ramp in order to prevent sub harmonic oscillations so a ramp is generated in the controller (TL3843) [14], [15].

The two converters need to work in parallel, so in order to 
TABLE III

Dual $180^{\circ}$ Shifted Boost Simulation Results

\begin{tabular}{|c|c|c|c|c|}
\hline Mode & Parameter & Symbol & Value & Unit \\
\hline & Input Voltage & $\mathrm{V}_{\text {IN }}$ & 240 & $\mathrm{~V}$ \\
& Output Voltage & $\mathrm{V}_{\text {OUT }}$ & 530 & $\mathrm{~V}$ \\
\hline Full Power & Output Current & $\mathrm{I}_{\text {OUT }}$ & 57 & $\mathrm{~A}$ \\
$(30 \mathrm{~kW})$ & Capacitor Current & $\mathrm{I}_{\text {C RMS }}$ & 24.6 & $\mathrm{~A}$ \\
\hline Mid Power & Output Current & $\mathrm{V}_{\text {OUT }}$ & 29.5 & $\mathrm{~A}$ \\
$(15 \mathrm{~kW})$ & Capacitor Current & $\mathrm{I}_{\text {C RMS }}$ & 18.1 & $\mathrm{~A}$ \\
\hline
\end{tabular}

TABLE IV

RESULTS FOR MAXIMUM POWER TEST

\begin{tabular}{|c|c|c|c|}
\hline Parameter & Symbol & Value & Unit \\
\hline Load Resistor & $\mathrm{R}_{\mathrm{L}}$ & 18 & Ohm \\
Output Voltage & $\mathrm{V}_{\text {OUT }}$ & 528 & $\mathrm{~V}$ \\
Boost Inductance & $\mathrm{L}$ & 142 & $\mathrm{uH}$ \\
Output Power & $\mathrm{P}_{\text {OUT }}$ & 15.4 & $\mathrm{~kW}$ \\
Efficiency & $\mathrm{N}$ & 95 & $\%$ \\
\hline
\end{tabular}

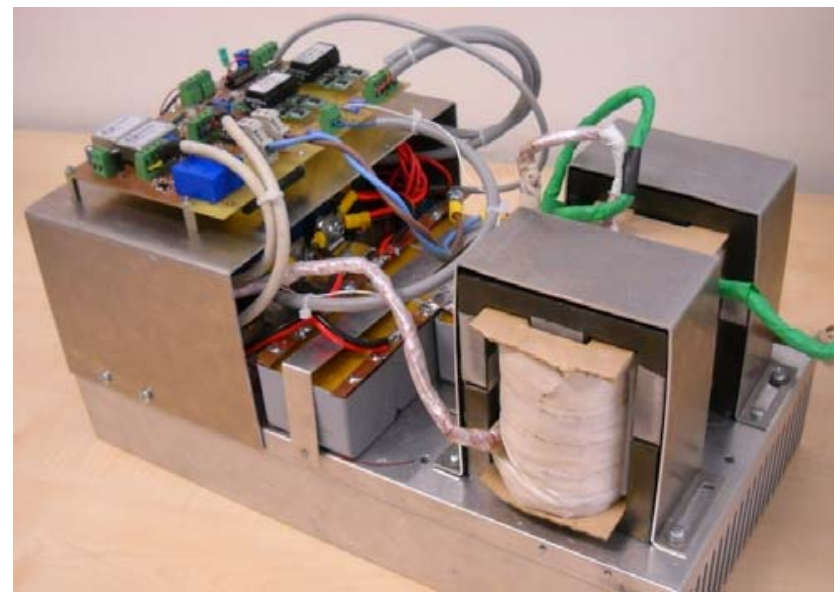

Fig. 6. Photograph of the prototype.

equally divide the output current in each converter; one of them measures the output voltage, compares it with a reference and generates an error signal. This signal, shown with a dotted line in Fig. 5, is shared by both controllers, so the first controller has a voltage loop and a current loop, while the other controller only has a current loop. This is a low-cost analog control; other alternative is to use a DSP [16].

\section{G. Buck Controller Stage (Regenerating)}

In this case only one controller is required because the charge current can be produced by a single boost (50A).

The Buck controller uses a ramp generated internally like in a voltage-mode controller but measures the battery current and compares it with an adjustable reference. This current is the inductor average current, so the signal arrives at the controller

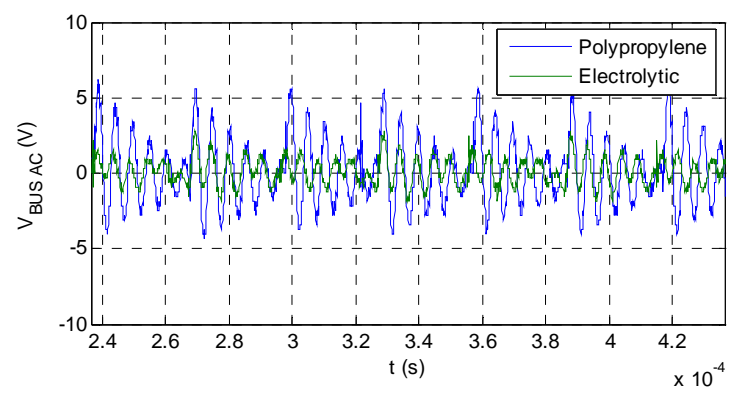

Fig. 7. Output voltage comparison due to different output capacitors at $15 \mathrm{~kW}$.
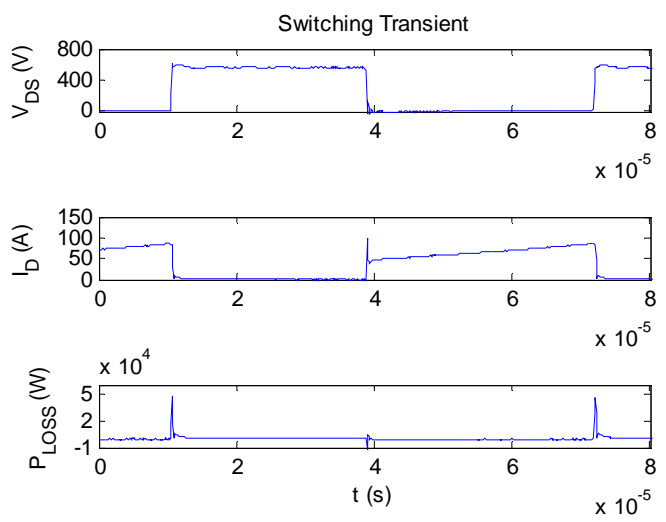

Fig. 8. Switching at nominal power.

through a low-pass filter. The reference can be adjustable from $40 \mathrm{~A}$ to $50 \mathrm{~A}$.

\section{SIMULATIONS}

In order to study the current ripple, the dual boost is simulated in PSIM. The results, shown in Fig. 4 with crosses, indicate that the current ripple with the chosen inductance is below the limit of 26A imposed by the capacitor selection. The maximum $I_{C R M S}$ and $\mathrm{I}_{\mathrm{O} \text { AVG }}$ ratio is 0.43 (24A). Simulations are achieved at two power levels, $30 \mathrm{~kW}$ and $15 \mathrm{~kW}$, with the following purposes: the first one is to predict the converter the behavior at full power and the second one is to confirm that simulation results are close to the real captures. The prototype is tested at $15 \mathrm{~kW}$ in phase shift mode. Table III summarizes the results; the capacitor current for the same circuit at mid-power level is $18 \mathrm{~A}$.

\section{RESUlts}

The prototype is shown in Fig. 6, where the two coils, the switches, the capacitors and the control board can be observed. The system is placed in a heat-sink with forced air cooling. In order to test the system at nominal power, four different experiments are carried out.

First, only one boost stage is tested at nominal power 


\section{TABLE V}

RESULTS FOR REGENARATIVE POWER TEST

\begin{tabular}{|c|c|c|c|}
\hline Parameter & Symbol & Value & Unit \\
\hline Output Voltage & $\mathrm{V}_{\text {OUT }}$ & 285 & $\mathrm{~V}$ \\
Input Voltage & $\mathrm{V}_{\text {OUT }}$ & 500 & $\mathrm{~V}$ \\
Output Current & $\mathrm{I}_{\text {BAT }}$ & 51 & $\mathrm{~A}$ \\
Input Current & $\mathrm{I}_{\text {REG }}$ & 31 & $\mathrm{~A}$ \\
Output Power & $\mathrm{P}_{\text {OUT }}$ & 15.1 & $\mathrm{~kW}$ \\
Efficiency & $\mathrm{n}$ & 95 & $\%$ \\
\hline
\end{tabular}
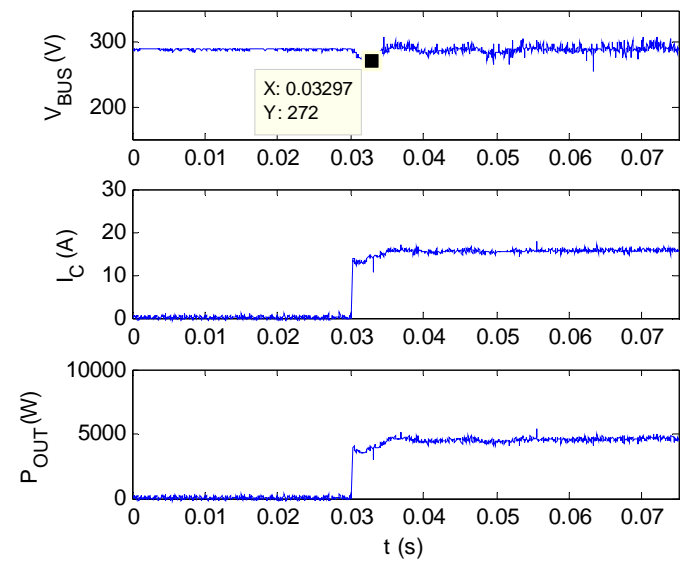

Fig. 9. Load step at reduced voltage keeping the $18 \mathrm{Ohm}$ load resistor.

$(15 \mathrm{~kW})$ to measure its efficiency. Table IV shows the results. The output load is an $18 \mathrm{Ohm} 20 \mathrm{~kW}$ resistor, and the power supply is a 250V-80A source. Fig. 7 shows an output voltage ripple comparison obtained from using electrolytic or polypropylene alternatives. The ripple is increased using the polypropylene capacitors but it is still within the initially specified voltage ripple limits (Table I). Despite the ripple increase, the longer life-time quality makes polypropylene solution more desirable. Fig. 8 shows the switching waveform at full load steady-state condition and shows a step in the load to see the output voltage variation. It can be observed that the voltage drops $10 \%$. The test is carried out at a lower power due to a limitation in our facility (5kW).

In the second experiment, both boost converters are linked and tested at $15 \mathrm{~kW}$. The output current is now equally provided by the two converters, so the power transfer for each one drops to $7.5 \mathrm{~kW}$. This test shows the phase shifted parallel mode. Figure 10 shows the current in each inductor.

Fig. 11 shows the current ripple in the output capacitor. It compares the two topologies: the single boost and the dual phase shifted boost, for the same output power. In both cases the output current is $30 \mathrm{~A}$ and the input voltage is $240 \mathrm{~V}$ so the duty is 0.55 . The RMS current for the single stage is $31 \mathrm{~A}$ $\left(1.03 I_{\text {OUT }}\right)$ and in $19 \mathrm{~A}\left(0.63 I_{\text {OUT }}\right)$ in the dual converter. The reduction is considerable, and it is also close to the value

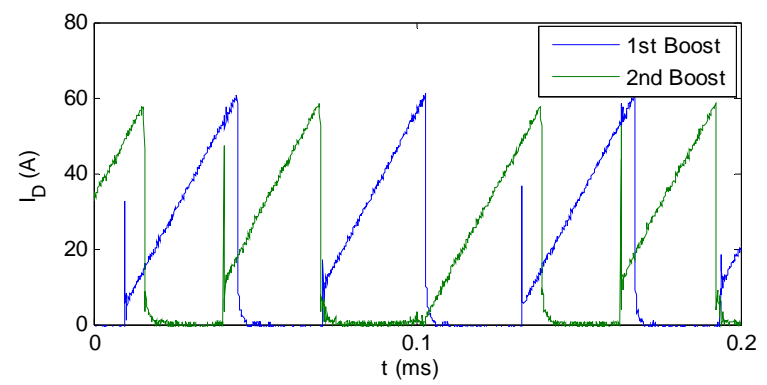

Fig. 10. Inductor current in each converter.

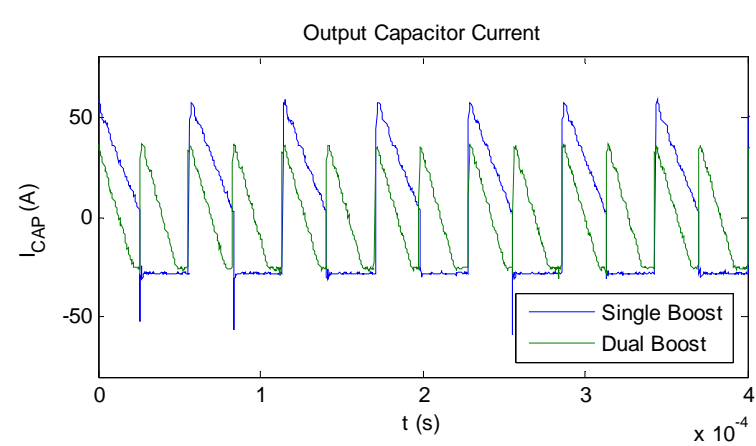

Fig. 11. Comparison between single boost and dual boost for the same power $(15 \mathrm{~kW})$.
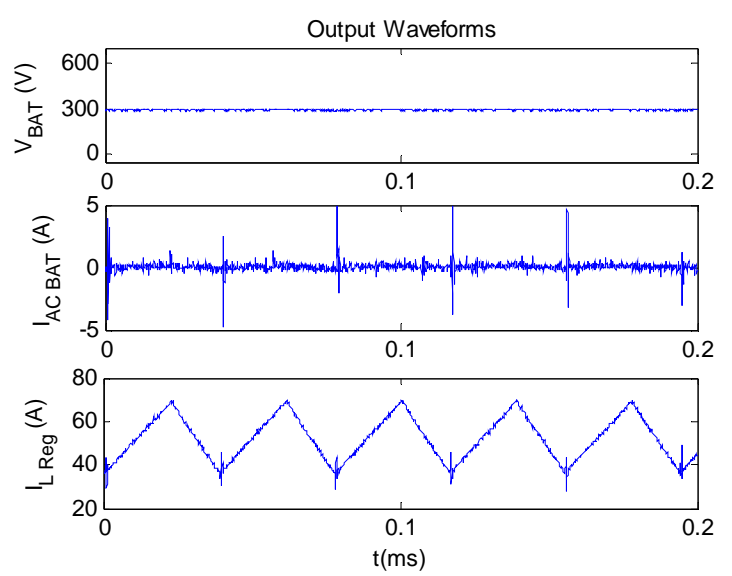

Fig. 12. Output waveforms in the regenerative direction.

predicted by the simulation (Table III).

A third experiment is presented to validate the regenerative mode of the design. The output voltage is reduced from $530 \mathrm{~V}$ to $500 \mathrm{~V}$ because of equipment limitations. This restriction does not compromise the design validation. The ripple, the efficiency and the output current are measured. The output values are shown in Fig. 12. The battery voltage reaches $290 \mathrm{~V}$ and the average inductor current is $51 \mathrm{~A}$, which is the average battery current. The current ripple is reduced due to the inductor and a capacitor in parallel with the batteries (input side filter).

Fig. 13 shows the diode switching waveforms in this mode 

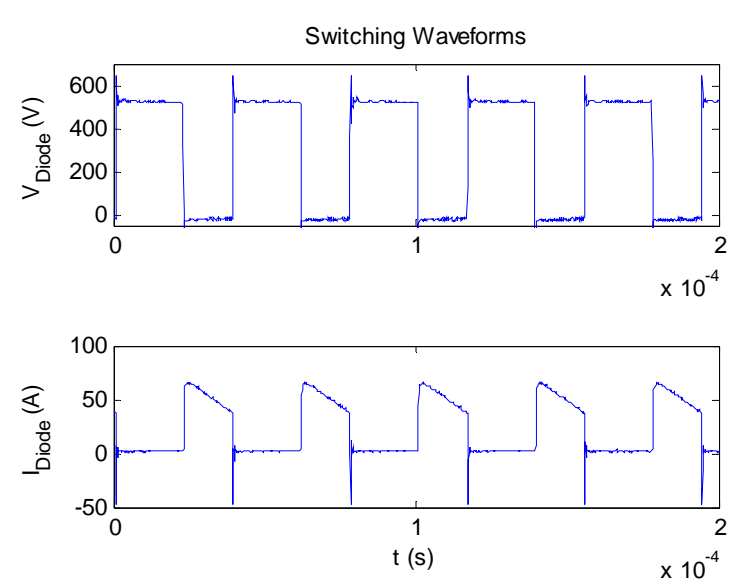

Fig. 13. Diode switching waveforms in the regenerative mads

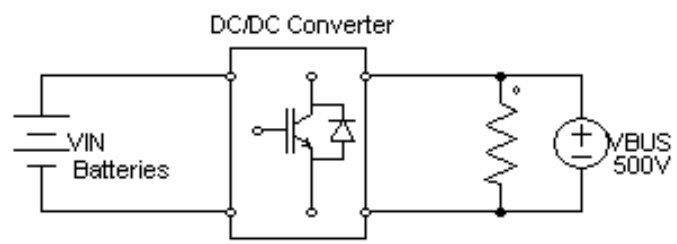

Fig. 14. Mode change experiment test-bench.
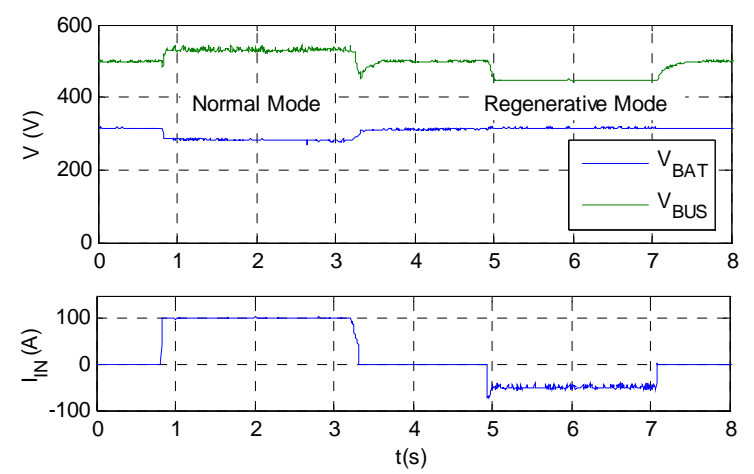

Fig. 15. Complete cycle, normal and regenerative mode switching.

where the switching voltage spikes are reduced using a snubber capacitor. Table $\mathrm{V}$ summarizes the regenerative mode test results.

Finally, a mode change experiment is presented. A test bench was constructed using a battery pack in the low voltage side and a load in parallel with a power supply in the high voltage side, as shown in Fig. 14. This test shows the power flow in the two directions. In the normal mode the system delivers $100 \mathrm{~A}(\sim 30 \mathrm{~kW})$ from the battery and, in the regenerative mode, the high voltage bus charges the battery with a current of 50A ( 15kW). Fig 15 shows input and output voltages and the battery current. The bus voltage does not instantaneously recover after each mode. This is due to the test-bench DC source soft-start (500V Bus), so it is not a problem of the converter.

\section{CONCLUSIONS}

A complete design of a $30 \mathrm{~kW}$ bidirectional DC-DC converter has been detailed based on a dual $180^{\circ}$ shifted boost converter. A prototype has been built and tested.

Firstly, the proposed design studies the frequency range which predicts an efficiency of $96 \%$. The actual efficiency has proved to be consistent (95\%).

Both modes have been tested at full power. The given results show an optimum performance of the converter in both directions. Furthermore, the waveforms that characterized each mode have been observed and discussed.

The voltage and current spikes that appear in the switching process can be seen in figures 8,10 and 13 . The voltage spikes are reduced using a snubber capacitor.

The system is adjusted so that the total current is equally split between the two converters (Fig. 10). This way, it is assured that both converters always operate in the same condition.

A phase shift topology has been used to reduce the current ripple. This reduction is confirmed by the experiment results and hence, a capacitor branch can be eliminated and the volume reduced.

Finally, a load variation test has been achieved to analyze the compensation control. It can be concluded that the designed prototype dynamic response (Fig. 9) is within the output voltage variation specification limit (5\%).

The designed and implemented $30 \mathrm{~kW}$ converter has proved to show an optimum performance within the specifications. This paper is not only an example but also a guideline for power electronic design in electric vehicle applications.

\section{REFERENCES}

[1] B. Lee, D. Shin, H. Song, H. Heo, and H. Kim, "Development of an advanced hybrid energy storage system for hybrid electric vehicles," Journal of Power Electronics, Vol. 9, No. 1, pp. 51-60, Jan. 2009.

[2] S. S. Williamson, S. C. Rimmalapudi, and A. Emadi, "Electrical modelling of renewable energy sources and energy storage devices,” Journal of Power Electronics, Vol. 4, No. 2, pp. 117-126, Apr. 2004.

[3] L. Zhu, "A novel soft-commutating isolated boost full-bridge ZVS-PWM DC-DC converter for bidirectional high power applications,” IEEE Trans. Power Electron., Vol. 21, No. 2, pp. 422-429, Mar. 2006.

[4] Y. Du, X. Zhou, S. Bai, S. Lukic, and A. Huang, "Review of non-isolated bi-directional DC-DC converters for plug-in hybrid electric vehicle charge station application at municipal parking decks," in Applied Proc. Power Electronics Conference and Exposition (APEC), Twenty-Fifth Annual IEEE, pp. 1145-1151, 2010.

[5] A. Alonso, J. Sebastian, D. Lamar, and M. Hernando, “An overall study of a dual active bridge for bidirectional DC/DC conversion," in Proc. Energy Conversion Congress and Exposition (ECCE), pp. 1129-1135, 2010.

[6] J. Hu, Y. Chen, and Z. Yang, "Study and simulation of one bi-directional DC/DC converter in hybrid electric vehicle," in Proc. $3^{\text {rd }}$ International Conference on Power Electronics Systems and Applications, pp. 1-4, 2009. 
[7] S. Jalbrzykowski, A. Bogdan, and T. Citko, “A dual full bridge resonant class-e bidirectional dc-dc converter," IEEE Trans. Ind. Electron., Vol. 58, No. 9, pp. 3879-3883, Sep. 2011.

[8] M. Taherbaneh, A. H. Rezaie, H. Ghafoorifard, M. Mirsamadi, and M. B. Menhaj, "A trade-off between the efficiency, ripple and volume of a DC-DC converter," Journal of Power Electronics, Vol. 11, No. 5, pp 621-631, Sep. 2011

[9] P. L. Dowell, "Effects of eddy currents in transformer windings", in Proceedings of the Institution of Electrical Engineers, pp. 1387 - 1394, 1966.

[10] V. Valchev, A. Van den Bossche, Inductors and Transformers for Power Electronics, CRC Press, Chap. 5, 2005.

[11] W. Li, G. Joos, and C. Abbey, “A parallel bidirectional DC/DC converter topology for energy storage system in wind applications," in Proc. Industry Applications Conference, 42nd IAS Annual Meeting, pp. 179-185, 2007.

[12] H. Ertl, T. Wiesinger, J. W. Kolar, and F. C. Zach, "A Simple Active Method to Avoid the Balancing Losses of DC Link Capacitors," in 24th International Conference on Power Electronics (PCIM), pp: 1-6, 2003.

[13] P. Grbovic, "Loss-free balancing circuit for series connection of electrolytic capacitors using an auxiliary switch-mode power supply," IEEE Trans. Power Electron., Vol. 24, No. 1, pp. 221-231, Jan. 2009.

[14] B. Bryant and K. Kazimierczuk, "Open-loop power-stage transfer functions relevant to current-mode control of boost PWM converter operating in CCM," IEEE Trans. Circuits Syst. I, Reg. Papers, Vol. 52, No. 10, pp. 2158-2164, Oct. 2008.

[15] C. Basso, Switch-Mode Power Supplies Spice Simulations and Practical Designs, McGrawHill, Chap. 2-3, 2008.

[16] O. Ellabban, J. Van Mierlo, and P. Lataire, “A DSP-based dual loop digital controller design and implementation of a high power boost converter for hybrid electric vehicles applications,” Journal of Power Electronics, Vol. 11, No. 2, pp. 113-119, Mar. 2011.

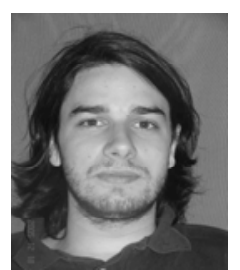

Federico Ibáñez was born in Buenos Aires, Argentina in 1982. He received the B.S. degrees in electronic engineering from National Technologic University (UTN) in Buenos Aires (2008). Since 2006 to 2009, he has been part of Electronics Department of UTN. Nowadays he is working in the Power Electronics Group of CEIT-University of Navarra, San Sebastián, Spain where he is currently a $\mathrm{PhD}$ Student. His research interests are in the areas of high power DC/DC converters for applications with supercapacitors and renewable energy.

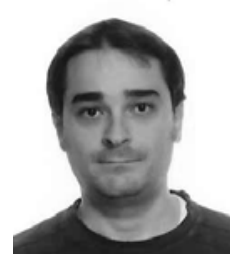

Javier Vadillo was born in Bilbao, Spain in 1978. He received the B.S. degrees in Electronic Engineering and Physics from the University of the Basque Country (UPV/EHU) and the University of Cantabria, Spain, in 2002 and 2003 respectively, and the Ph.D. degree in electronics and communications program from the University of Navarra, Spain, in 2011. Since 2004, he has been with the Electronics and Communications department in CEIT research centre, in San Sebastian, Spain. He is also a lecturer in TECNUN-University of Navarra. His research interests are in the areas of AC/AC matrix converters, electrical energy storage systems (Supercapacitors, flywheels and batteries) and high frequency DC/AC power converters oriented to renewable applications.

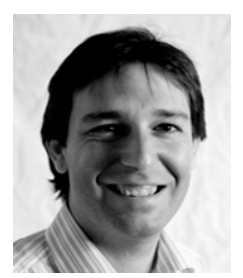

Miguel Martínez-Iturralde Maiza is a researcher in the Department of Electronics and Communications at CEIT. He received his degree in Industrial Engineering (2001) and his $\mathrm{PhD}$ degree (2005) from the University of Navarra. His main research interests and expertise are in the field of the design and control of electrical machines. mainly in the following points: advanced electrical direct drive systems, design and development of traction systems for sustainable transport, electromagnetic design: Linear and rotary actuators. Axial flux, radial flux and transversal flux machines. High speed machines and advanced drive control: Vector control, sensorless control, DTC.

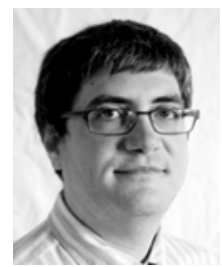

José Martín Echeverría was born in San Sebastian, Spain in 1972. He received his $\mathrm{PhD}$ degree (2005) and his MSc degree in electrical engineering (1996) from the University of Navarra. He started to work as researcher at CEIT in 1997 and has been associate professor at the University of Navarra since 2011. Currently he works in the Electronic and Communications Department at CEIT within the Industrial and Power systems group. He has been involved in international and national projects related to power electronics, energy storage technologies and the development of intelligent power electronics converters. 